\title{
Traumatic retinopathy presenting as acute macular neuroretinopathy
}

\author{
Martin M Nentwich, ${ }^{1}$ Anita Leys, ${ }^{2}$ Andreas Cramer $^{3}$ Michael W Ulbig ${ }^{1}$
}

\begin{abstract}
- Additional material is published online only. To view please visit the journal online (http://dx.doi.org/10.1136/ bjophthalmol-2013-303354).

${ }^{1}$ Department of Ophthalmology, LudwigMaximilians-University, Munich, Germany ${ }^{2}$ Department of Ophthalmology, University of Leuven, Leuven, Belgium ${ }^{3}$ Department of Ophthalmology, Landeskrankenhaus Vöcklabruck, Vöcklabruck, Austria
\end{abstract}

\section{Correspondence to} Dr Martin M Nentwich, Department of Ophthalmology, Ludwig-Maximilians-University, Mathildenstrasse 8, Munich 80336, Germany; Martin. Nentwich@med.uni-muenchen. de

Received 10 March 2013 Revised 19 June 2013 Accepted 26 June 2013 Published Online First 12 July 2013
To cite: Nentwich MM, Leys A, Cramer A, et al. Br J Ophthalmol 2013:97: 1268-1272.

\section{ABSTRACT}

Aim Traumatic retinopathy presenting as acute macular neuroretinopathy (AMNR) is an uncommon disease causing paracentral scotomas after indirect trauma. Methods We report on five patients (six eyes) with AMNR with a temporary reduction of visual acuity and persistent paracentral scotomas after indirect trauma. The findings were documented using multimodal imaging and the follow-up was up to 32 months.

Results Initially, fundoscopy was unremarkable in all patients while visual acuity (Snellen equivalents) varied between 0.03 and 1.0, and a paracentral scotoma was present in all patients. During follow-up, visual acuity recovered to 1.0 in all patients while the paracentral scotomas persisted. Spectral-domain optical coherence tomography revealed a disruption of the inner/outer segment junction within the macular lesion and changes in the outer nuclear layer, which slowly recovered partly during the follow-up.

Conclusions These findings suggest that indirect trauma can cause changes in the outer retina resembling those seen in AMNR, resulting in persisting paracentral scotomas.

\section{INTRODUCTION}

Acute macular neuroretinopathy (AMNR) is a rare disease characterised by wedge-shaped dark macular lesions resulting in paracentral scotomas, which was described for the first time by Bos and Deutman in $1975 .{ }^{1}$ The advent of optical coherence tomography (OCT) showed defects at the level of the photoreceptor outer segments with alterations of in the inner/outer (IS/OS) segment junction within the macular lesion. The name 'acute macular outer retinopathy' was suggested for this condition. ${ }^{2}$ A history of flu-like symptoms has been reported in many affected patients, especially in more recent publications. ${ }^{3}$ The macular lesions are frequently bilateral but usually asymmetric, and sometimes subtle and easily overlooked unless AMNR is suspected and the eye is carefully examined with red-free light.

In 1997, Gillies et al ${ }^{4}$ published a case series of four patients (four eyes) presenting with lesions and symptoms resembling AMNR, which were noted after indirect trauma; in three out of the four cases this was due to a car accident.

However, the exact location of the defect could not be determined in this report due to the absence of OCT. To the best of our knowledge, since this case series, no other reports of traumatic retinopathy presenting as AMNR have been published.

\section{MATERIALS AND METHODS}

We identified trauma-induced AMNR in five patients (six eyes) and report typical findings observed with multimodal imaging (visual fields: Humphrey Field Analyzer; microperimetry: Nidek, Hiroishi, Japan; Infrared scanning laser ophthalmoscopy (IR-SLO) and spectral-domain OCT (SD-OCT): SpectralisOCT, Heidelberg Engineering, Heidelberg, Germany; multifocal electroretinogram (mERG): Roland Consult, Brandenburg, Germany). Visual acuity is reported using standard metric Snellen equivalents.

\section{RESULTS}

The period of review for four of the cases presented is between 3 and 32 months, while one patient did not present for follow-up examination.

\section{Case 1}

A 68-year-old man was involved in a moderately severe car accident and experienced a bilateral tibial fracture. There was no loss of consciousness and no direct ocular trauma. However, directly after the accident he noticed a paracentral scotoma and a loss of vision in his left eye. At initial examination 11 days after the accident, visual acuity was 0.03 and a marked visual field defect off the centre in the left eye was seen (figure 1D). IR-SLO imaging showed a dark, wedge-shaped defect in the nasal part of the macular area (figure 1A). In the same region, SD-OCT visualised a disruption of the IS/OS segment junction with defects at the level of the photoreceptor outer segments and increased reflectivity of the outer nuclear layer (ONL) (figure 2A). Fluorescein angiography was unremarkable and did not identify any leakage due to vascular damage. Fundoscopy revealed hardly visible, ill-defined changes to the nasal macular region resembling slight retinal thickening. Visual acuity in the right eye was 1.0, visual fields were normal and no maculopathy was identified.

Visual acuity of the left eye improved over time ( 0.5 at 1 week, 1.0 at 1 year) and partial restoration of the IS/OS junction was seen, while the scotoma persisted, as verified by microperimetry (figure 1B-F). At 32 months after trauma, a slight retinal thinning at the level of the ONL was seen exactly in the area of the formerly dark lesion (figure 2C,D). In a telephone interview 56 months after the accident, the patient reported unchanged paracentral scotomas in the left eye.

\section{Case 2}

A 48-year-old woman reported loss of vision and a paracentral grey spot in her right eye, which she had noted directly after a car accident without any direct ocular trauma some days before. Visual acuity at time of first presentation was 0.1 in the right and 0.8 in the left eye. While fundoscopy 


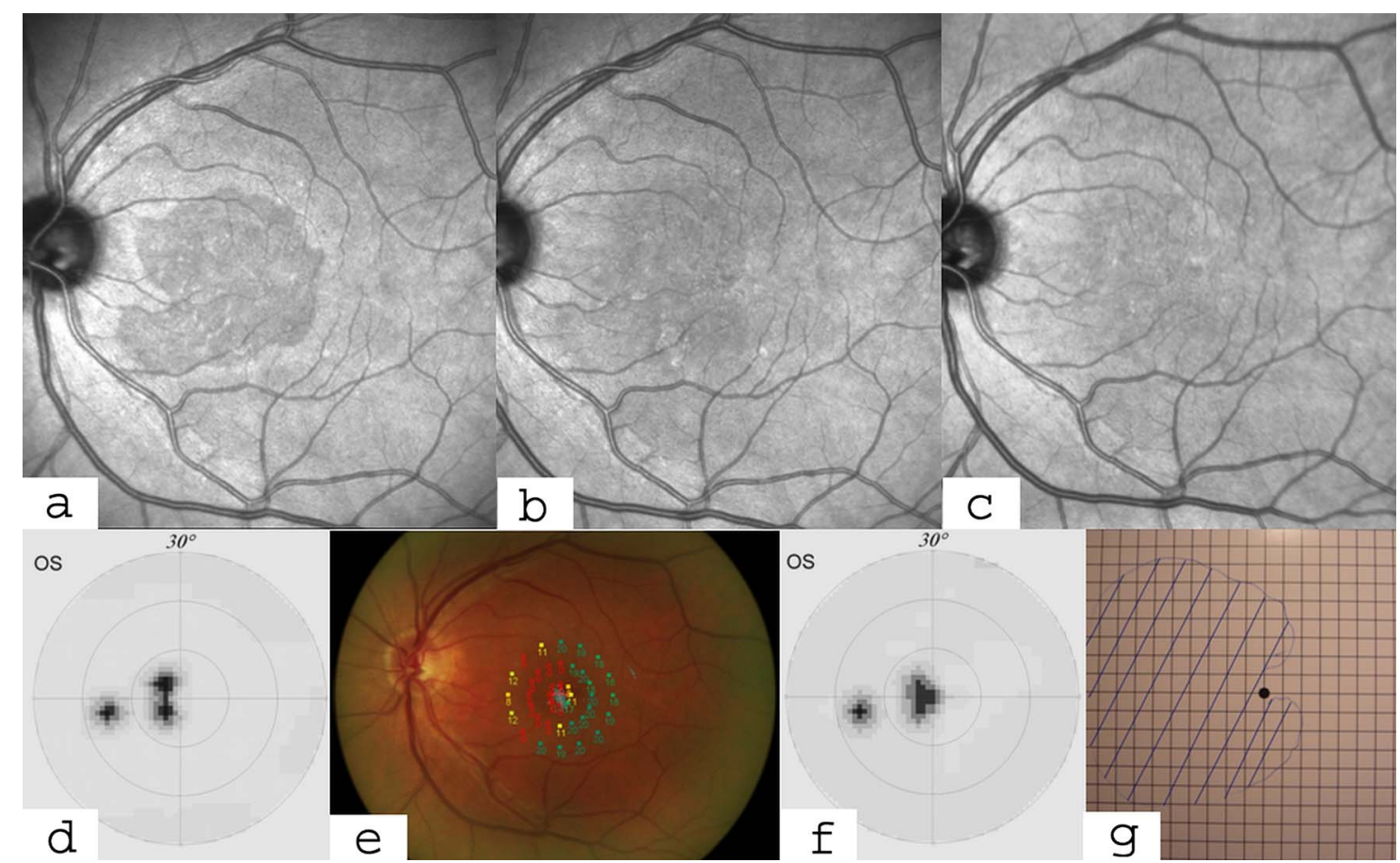

Figure 1 Case 1: infrared scanning laser ophthalmoscopy imaging and visual fields. On the infrared images the gradual restoration of the normal fundus colour appearance over time can be seen, while the paracentral scotoma persists. (A) 11 days after trauma; (B) 11 months after trauma; (C) 32 months after trauma; (D) 11 days after trauma; (E) 22 months after trauma; $(F, G) 32$ months after trauma. Access the article online to view this figure in colour.

only showed a small parafoveal haemorrhage and fluorescein angiography was unremarkable, IR-SLO and SD-OCT revealed a darker lesion, IS/OS defects, a reduced transparency to the retina starting at the level of the outer plexiform layer and increased reflectivity of the ONL in the acute lesions. Also in this case, visual acuity recovered quickly (0.8 11 days and 1.0 22 days after trauma) while IS/OS defects persisted during 3 months follow-up (figure 3).
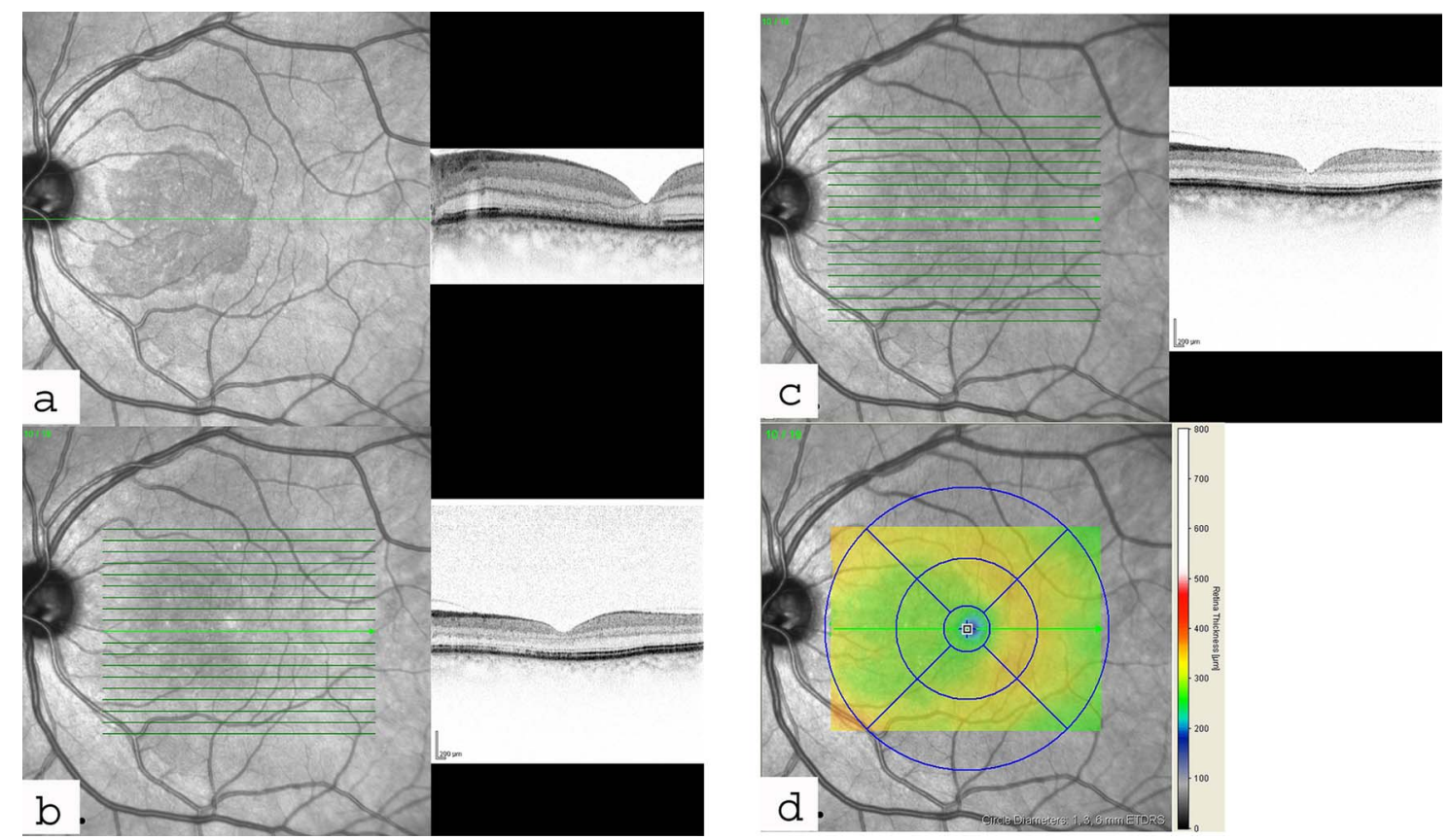

Figure 2 Case 1: infrared picture of the lesion. Spectral-domain optical coherence tomography shows disruption of the inner/outer (IS/OS) segment junction with defects at the level of the photoreceptor outer segments, increased reflectivity of the outer nuclear layer in the acute lesions and the change over time. In the later follow-up it is evident that the retinal thinning is mainly to be seen at the level of the outer nuclear layer. (A) 11 days after trauma; (B) 22 months after trauma; $(C, D) 32$ months after trauma. Access the article online to view this figure in colour. 

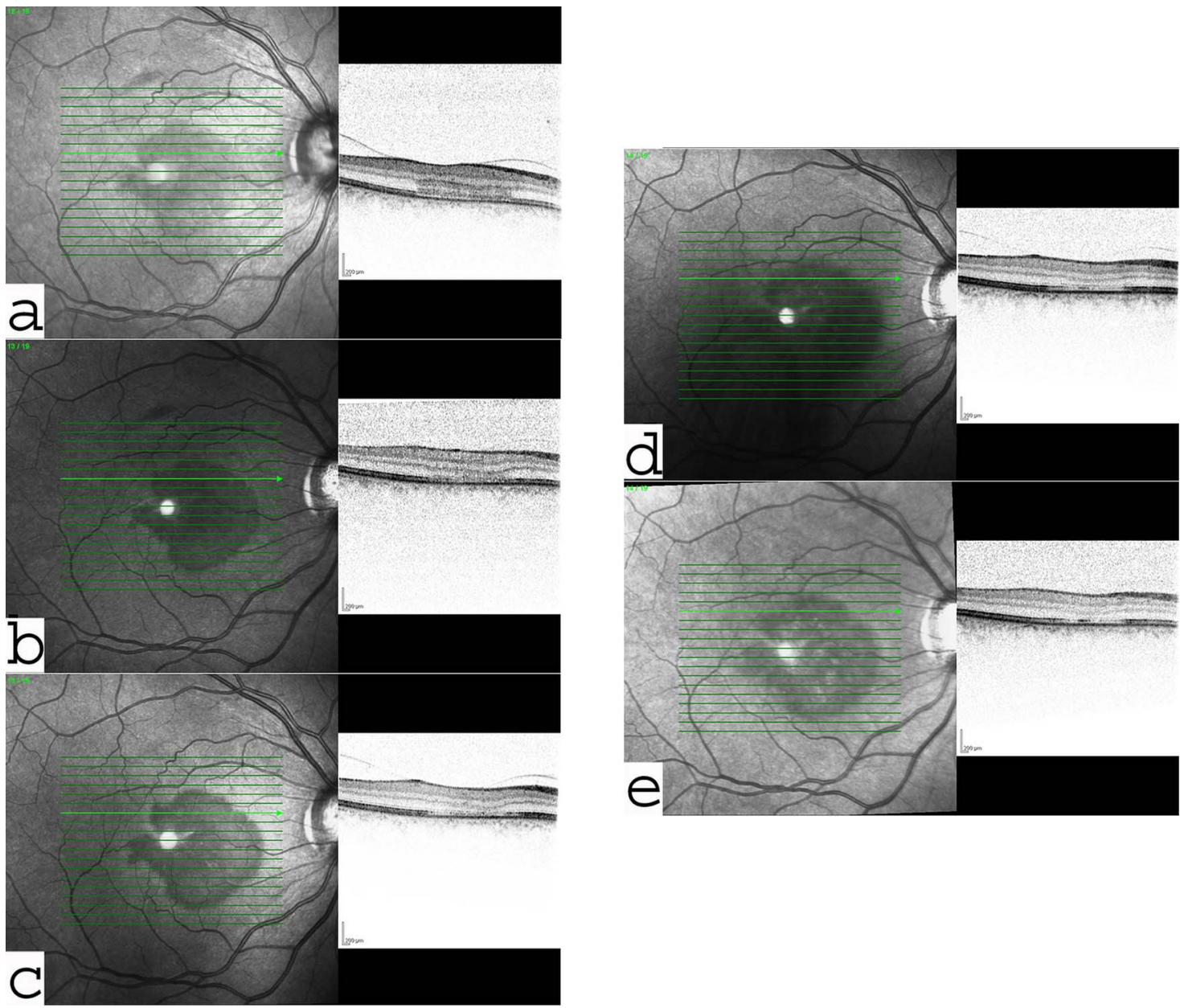

Figure 3 Case 2: infrared picture and spectral-domain optical coherence tomography of the lesion. Spectral-domain optical coherence tomography shows disruption of the inner/outer (IS/OS) segment junction with defects at the level of the photoreceptor outer segments, a reduced transparency to the retina starting at the level of the outer plexiform layer, increased reflectivity of the outer nuclear layer in the acute lesions and the change over time. (A) 4 days after trauma; (B) 11 days after trauma; (C) 22 days after trauma; (D) 2 months after trauma; (E) 3 months after trauma. Access the article online to view this figure in colour.

\section{Case 3}

A 21-year-old woman experienced a severe car accident without any direct trauma to the eyes. Immediately after the accident the patient noticed a white spot in the left eye that changed into a dark spot several hours later. This spot exactly corresponded to a scotoma observed on Amsler grid as well as during perimetry and to a dark area on IR-SLO (figure 4). The right eye had a small lesion of AMNR nasal and superior of the fovea and there was a corresponding small scotoma that had not been noticed by the patient to date. Visual acuity was 1.0 in both eyes. Fluorescein angiography did not show any signs of vascular damage. However, mERG revealed an asymmetrical response with reduced amplitudes in the left eye and normal response in the right eye. At last examination, 13 months later, the spots remained disturbing and the scotoma was unchanged, although fundus examination showed that the dark lesion had faded. At 13 years after the event the patient reported in a telephone interview that she could still see the spot in front of the left eye and sent a recent Amsler grid (figure 3C).

\section{Case 4}

A patient in their 40 s noted a spot on their right eye on the second day after a car accident in which the patient had experienced a contusion of the face but no ocular trauma. This spot corresponded with a dark area in the macular region on red-free and SLO-IR images. Visual acuity was 1.0 for both eyes and fluorescein angiography was unremarkable. Stratus 1 OCT imaging, available at the time of presentation, had poor resolution of the macular details and did not visualise any welldefined abnormalities. However, mERG showed an asymmetrical response with reduced amplitudes in the right eye compared to normal findings in the left eye. Further tests revealed corresponding scotomas on Amsler grid and Humphrey perimetry and lesions on IR-SLO (figure 5).

\section{Case 5}

A patient in his early 30 s was affected by a car accident during which the car turned upside down but without any direct trauma to the eyes. Since the accident, the patient has reported three spots in his right eye, while visual acuity was not affected. Fundoscopy and fluorescein angiography were unremarkable. IR-SLO depicted three paracentral lesions that were verified by Amsler grid (see online supplementary figure S6). The scotoma remained unchanged during the 25 months of follow-up.

\section{DISCUSSION}

Macular changes after indirect trauma have been attributed to localised vascular insufficiency as found in Valsalva retinopathy, 
Figure 4 Case 3: (A) infrared scanning laser ophthalmoscopy picture of the lesion in the left eye, 5 days after the accident. (B) Amsler grid showing the scotoma shortly after the event. (C) Amsler grid showing the scotoma 13 years later. (D) Scotoma on automated perimetry. (E) Multifocal electroretinogram (mERG) amplitudes are reduced in the left eye. (F) Red-free photograph of the right eye showing a small wedge-shaped lesion nasal and superior of the fovea. (G) mERG is normal in the right eye. Access the article online to view this figure in colour.
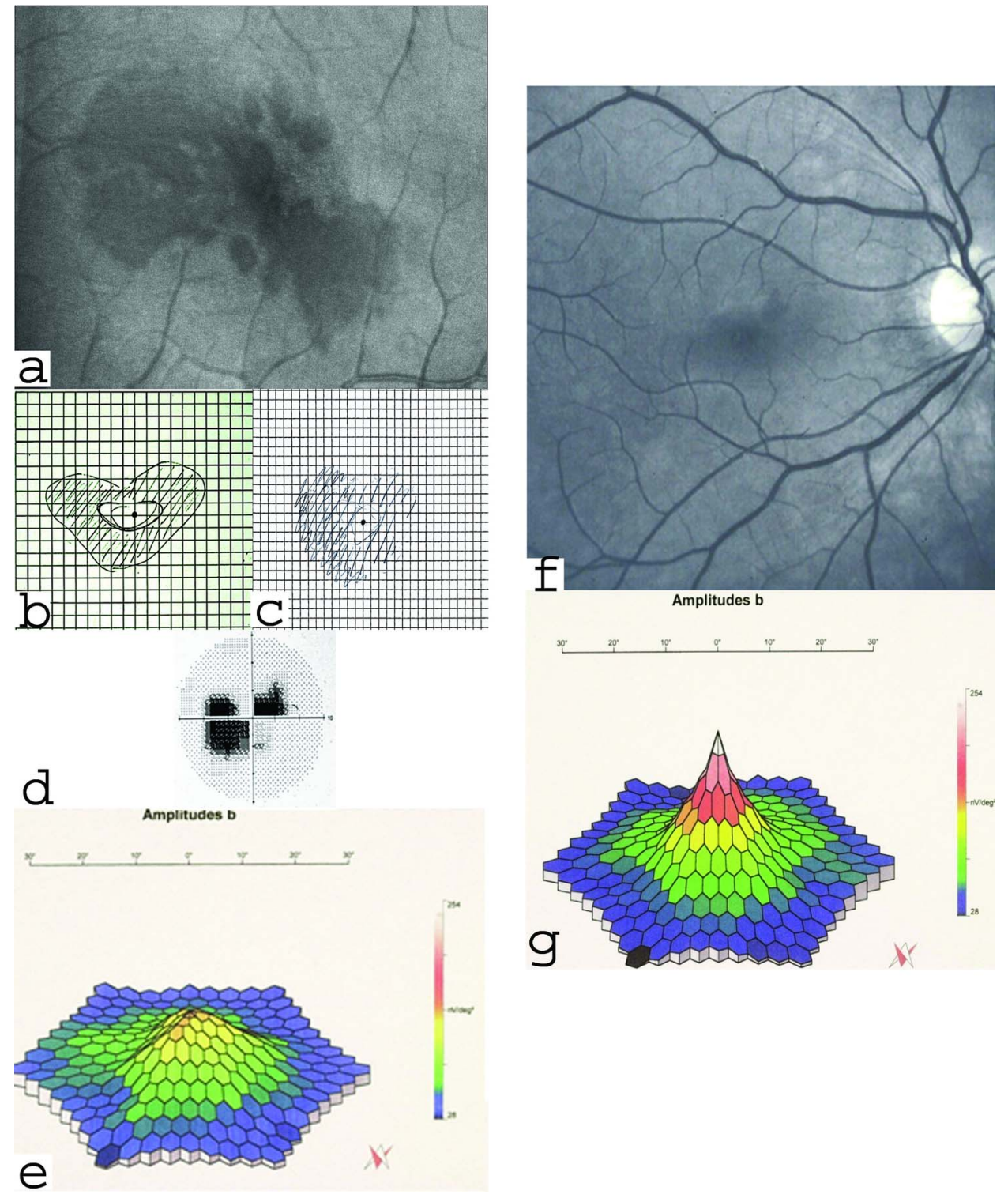

to systemic vascular damage as seen in fat embolism syndrome and to acute posterior vitreous detachment without any vascular changes. 45

Gillies et al were the first to describe indirect trauma as a possible cause of retinopathy resembling AMNR. They suggested a vascular aetiology and hypothesised that a sudden rise of intravascular pressure due to increased thoracic pressure associated with the accident (or coughing) may cause an acute breakdown of the capillary blood-retinal barrier. ${ }^{4}$ While the extravascular fluid would be removed quickly, the structural damage to the retina would persist. This is consistent with the persisting scotomas found during clinical follow-up examinations of the patients in the present series.

On fundoscopy the lesions corresponding to the visual field defect are difficult to detect, whereas IR-SLO imaging shows a dark, sometimes wedge-shaped lesion corresponding well to the visual-field defect found in microperimetry. ${ }^{6}$ This dark appearance of the lesions on IR imaging was also evident in the present series and might suggest damage of the Muller cells.

As Gillies' report was published before the advent of OCT imaging, the morphologic changes and their location within the retina were not described in detail in this publication. Regardless, the authors suggested that the lesions may be located in the outer retina based on biomicroscopy studies. ${ }^{4}$

In the present series, SD-OCT showed in cases 1 and 2 a disruption of the IS/OS segment junction with defects at the level of the photoreceptor outer segments. This is in line with recent reports of non-traumatic AMNR, where the same disruption of the IS/OS segment junction was described. ${ }^{2} 389$ Additionally, SD-OCT also revealed increased reflectivity of the ONL in the acute lesions. This may represent reactive Muller cell gliosis as increased reflectivity of the ONL is also seen in Macular telangiectasia type 2, in which Muller cell dysfunction has been implicated. $^{10}$

Also, after time a thinning of the outer retina was seen in the present series as described before in non-traumatic AMNR. ${ }^{9}$ During follow-up it is evident that this thinning is mainly located at the level of the ONL, likely reflecting loss of photoreceptors that is consistent with the characteristic enduring nature of the scotomas.

mERG has been shown to be reduced in AMNR. ${ }^{11} 12$ Though in the present series mERG was performed in only two 

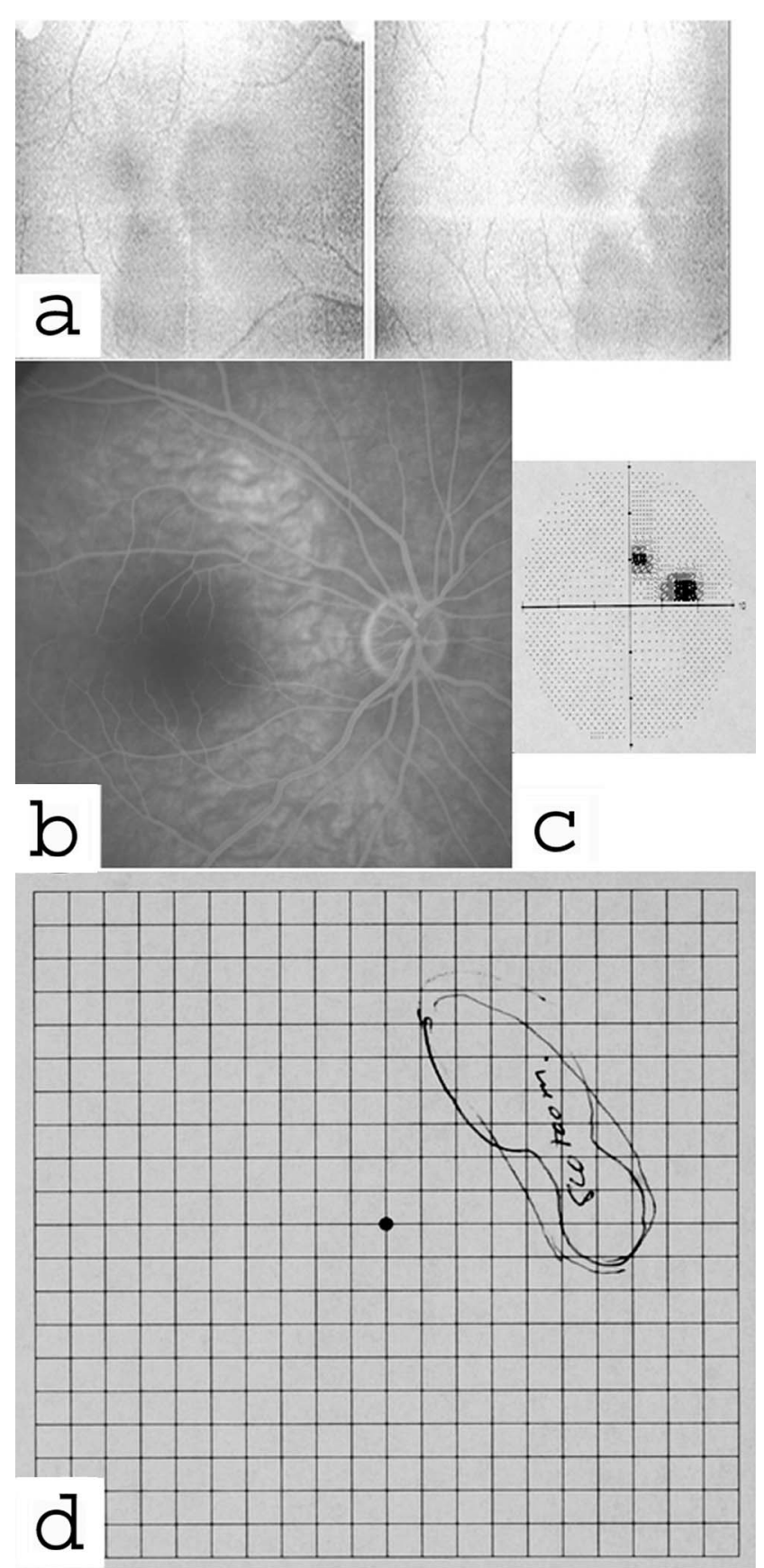

Figure 5 Case 4: (A) infrared images showing the darker appearance of the lesion; (B) fluorescein angiography with no sign of vascular damage; (C) automated perimetry depicts the scotoma; (D) Amsler grid showing the scotoma. patients (cases 3 and 4), in these cases reduced amplitudes were also found in the affected eye while the other eye was normal (figure 4).

The present cases show for the first time that traumatic retinopathy as described by Gillies can actually present like AMNR, displaying the same changes on SD-OCT. Static, kinetic and microperimetry revealed deep visual field defects in the area of the lesion.

Therefore, we suggest indirect trauma to be included in the list of possible causes of AMNR, as doubts as to whether the cases described by Gillies et al represent true cases of AMNR have been overcome by the findings described in the present report.

Contributors All authors made substantial contribution to the conception and design, analysis and interpretation of data, the drafting and revising of the article and gave final approval of the version submitted to the BJO. MMN is responsible for the overall content as guarantor.

\section{Competing interests None.}

Patient consent Obtained.

Ethics approval Institutional Review Board, Department of Ophthalmology, Ludwig-Maximilians University, Munich, Germany.

Provenance and peer review Not commissioned; externally peer reviewed.

\section{REFERENCES}

1 Bos PJ, Deutman AF. Acute macular neuroretinopathy. Am J Ophthalmol 1975;80:573-84.

2 Hughes EH, Siow YC, Hunyor AP. Acute macular neuroretinopathy: anatomic localisation of the lesion with high-resolution OCT. Eye (Lond) 2009;23:2132-4.

3 Turbeville SD, Cowan LD, Gass JD. Acute macular neuroretinopathy: a review of the literature. Surv Ophthalmol 2003:48:1-11.

4 Gillies M, Sarks J, Dunlop C, et al. Traumatic retinopathy resembling acute macular neuroretinopathy. Aust NZ J Ophthalmol 1997;25:207-10.

5 Nentwich MM, Remy M, Schaller UC. Ocular fat embolism syndrome. Int Ophthalmol 2011;31:15-6.

6 Gandorfer A, Ulbig MW. Scanning laser ophthalmoscope findings in acute macular neuroretinopathy. Am J Ophthalmol 2002;133:413-15.

7 Priluck IA, Buettner $\mathrm{H}$, Robertson DM. Acute macular neuroretinopathy. Am J Ophthalmol 1978;86:775-8.

8 Maschi C, Schneider-Lise B, Paoli V et al. Acute macular neuroretinopathy: contribution of spectral-domain optical coherence tomography and multifocal ERG. Graefes Arch Clin Exp Ophthalmol 2011;249:827-31.

9 Vance SK, Spaide RF, Freund KB, et al. Outer retinal abnormalities in acute macular neuroretinopathy. Retina 2011;31:441-5.

10 Powner MB, Gillies MC, Tretiach $\mathrm{M}$, et al. Perifoveal müller cell depletion in a case of macular telangiectasia type 2. Ophthalmology 2010;117:2407-16.

11 Browning AC, Gupta R, Barber $C$, et al. The multifocal electroretinogram in acute macular neuroretinopathy. Arch Ophthalmol 2003;121:1506-7.

12 Chan WM, Liu DT, Tong JP, et al. Longitudinal findings of acute macular neuroretinopathy with multifocal electroretinogram and optical coherence tomography. Clin Experiment Ophthalmol 2005;33:439-42. 


\section{Traumatic retinopathy presenting as acute macular neuroretinopathy}

Martin M Nentwich, Anita Leys, Andreas Cramer and Michael W Ulbig

Br J Ophthalmol 2013 97: 1268-1272 originally published online July 12, 2013

doi: 10.1136/bjophthalmol-2013-303354

Updated information and services can be found at:

http://bjo.bmj.com/content/97/10/1268

These include:

Supplementary Supplementary material can be found at:

Material http://bjo.bmj.com/content/suppl/2013/07/12/bjophthalmol-2013-3033 54.DC1.html

References This article cites 12 articles, 0 of which you can access for free at: http://bjo.bmj.com/content/97/10/1268\#BIBL

Email alerting Receive free email alerts when new articles cite this article. Sign up in the service box at the top right corner of the online article.

Topic Articles on similar topics can be found in the following collections Collections

Neurology (1229)

Vision (579)

\section{Notes}

To request permissions go to:

http://group.bmj.com/group/rights-licensing/permissions

To order reprints go to:

http://journals.bmj.com/cgi/reprintform

To subscribe to BMJ go to:

http://group.bmj.com/subscribe/ 